\title{
The Ambassador Program: A Framework for Recruiting and Engaging Flexible Volunteers
}

\author{
Ike Obi ${ }^{1}$, Alexus Jimson-Miller ${ }^{2}$, Michaela $\mathrm{Hahn}^{3}$, Darik Hall ${ }^{4}$ \\ ${ }^{1}$ Center for Emerging Media Design and Development, Ball State University, Muncie, USA, iobi@bsu.edu \\ ${ }^{2}$ Center for Emerging Media Design and Development, Ball State University, Muncie, USA, amjimsonmill@bsu.edu \\ ${ }^{3}$ Center for Emerging Media Design and Development, Ball State University, Muncie, USA, mehahn@bsu.edu \\ ${ }^{4}$ Center for Emerging Media Design and Development, Ball State University, Muncie, USA, dahall@bsu.edu
}

\begin{abstract}
Volunteers are vital to the mission of nonprofit organizations. However, most nonprofits are struggling to recruit the volunteers they need to support their goals. Due to this difficulty, many of these organizations are seeking innovative techniques for recruiting and engaging volunteers in ways that are enriching, meaningful and productive. On the basis of this need we surveyed 55 participants, interviewed 10 users and conducted literature reviews on 30 materials to uncover insights into the best method for recruiting and retaining volunteers. Findings from the study revealed that most of the respondents were interested in a flexible and open-choice approach to volunteering. It also showed that the respondents would like to participate with their friends and that they wouldn't mind a reward for helping out such organizations. Based on these findings, we developed a flexible volunteer framework that could be implemented by nonprofits or any other organization that needs help recruiting volunteers. This paper should provide a clear understanding of the process, its benefits, and how to incorporate them into their current volunteer, recruitment, and engagement strategies.
\end{abstract}

KEYWORDS: flexible volunteering, non-profits, design thinking, transmedia storytelling, volunteer recruitment

\section{Introduction}

Volunteers are vital to the mission of nonprofit organizations. However, most nonprofits are struggling to recruit the volunteers they need to support their goals. Due to this difficulty, many of such organizations are seeking innovative techniques for recruiting and engaging volunteers in ways that are enriching, meaningful and productive. This paper proposes the use of a flexible volunteering framework to fill this gap. The framework was built upon the findings from a survey $(n=55)$, interviews $(n=10)$ and literature review $(n=30)$ that was conducted with samples from the target audience.

Flexible volunteering is as an approach to volunteer engagement that gives volunteers the freedom to choose how they want to support their favorite nonprofit organization or charity. This approach gives volunteers the freedom to determine the kinds of tasks in which they would want to participate and the frequency of their participation. According to Durham (2016):

What flexible volunteering really should be about is the ability to be able to help out by offering your services as a volunteer as and when it suits you with no regular pattern of commitment or a minimum stipulated number of hours each week. Therefore, one week you might choose to give an hour of your time, the next week 5 hours, then the following two weeks, you may choose not to devote any of your time to volunteering at all due to other commitments. (para. 4)

The need for a flexible approach to volunteering arose as a result of the observed limitations of traditional methods of volunteer recruitment and engagement. In the conventional process of recruiting and engaging volunteers, nonprofit associations typically establish a structure and then expect the recruited volunteers to work within those structures. Often, the volunteers are expected to adjust their schedule to suit those of the nonprofits. The organizations in most cases do not consider that the volunteers have other commitments that are equally important to them.

A flexible approach to volunteering differs from the traditional method in that the volunteers do not have to adhere to the strict a structure or timeline. For instance, the volunteers can pledge to complete simple tasks such as posting content about the organization on social media or organizing events of their own choosing. They can do this in a sequence and frequency that suits them. At the 
end of that task, they can choose to continue completing more of the simple tasks or move on. Some organizations decide to reward volunteers for every simple task they complete to encourage them to achieve more. This approach gamifies the volunteering experience, and in turn, makes it exciting for people to volunteer.

Flexible volunteering can also help non-profit organizations to tap into a pool of volunteers that might not have volunteered due to time constraints or geographic limitations. Equally, the approach allows such organizations to reach a much broader network of volunteers that would have been unreachable through traditional recruitment methods. Hence, nonprofits can benefit from this approach by structuring their activities in ways that makes it easy to distribute volunteer tasks across a broader network.

To prototype the process of recruiting and engaging flexible volunteers, we developed the following components: First, an ambassador program, which is a small pool of highly dedicated volunteers who were given the freedom and the flexibility to define how they want to assist the organization. Second, a digital platform, Oh, Goody, which is a brand engagement platform used to reward both the ambassadors and the other non-commissioned flexible volunteers for every task they complete. The Oh, Goody platform was also used to monitor volunteer engagement metrics and to manage the content directed to volunteers.

Though this project was initially researched and designed for the International Committee of the Red Cross (ICRC), our low-fidelity prototyping project partner was Big Brothers Big Sisters of East Central Indiana (BBBS ECI). BBBS ECI is a nonprofit organization that matches kids who need mentors with willing adults. We selected this project partner because they were having challenges recruiting and engaging prospective mentors. They were also having difficulty creating awareness for their mission and goals among their target audience.

\section{Background Research}

A significant number of non-profit organizations fail to use any system to learn about prospective volunteers or to improve service delivery. This claim is supported by research published by Sahni, Lanzerotti, Bliss and Pike (2017) which showed that 40-60\% of the surveyed non-profit organizations do not use any methodology to recruit and engage volunteers. The organizations that do not use any framework admitted that this makes their work inefficient and sometimes ineffective. The study went on to highlight that such organizations do not innovate until there is an obvious problem with their existing method of recruitment or service delivery (Sahni, Lanzerotti, Bliss \& Pike 2017). Another study found that nonprofit managers tend to base their decisions on their own experiences and knowledge. This approach leads them to adopt or adapt yesterday's solutions to today's problems (Barrett, Balloun, \& Weinstein 2005). Not using any framework to recruit and engage volunteers leads to missed opportunities for human resources, social impact, and influence. This approach may also deny them the opportunity to actualize their organizations' goals and to stay in touch with changing trends.

Furthermore, most nonprofits are facing challenges in recruiting volunteers and creating awareness for their mission and goals because of saturated media channels. According to Silverstein (2017) "reaching out to potential volunteers, donors, and a new audience has become more accessible through social media. However, this has also created a new problem in which nonprofits are reaching out to the same pool of prospective volunteers and donors" (para. 2). Ultimately, these organizations are competing with multiple other organizations that are trying to gain the attention of users. This competition makes it difficult for nonprofits to create awareness for their events and to reach out to potential volunteers.

In today's fast-paced digital environment being able to address problems and implement solutions quickly can be extremely advantageous, primarily when these problems concern volunteer recruitment and audience engagement. It can allow organizations to stay competitive in the quest for volunteer human resources while also creating awareness of their missions and goals. Hence, it is essential for organizations to study their audience to understand their pain points and to know their content and media preferences. Analyzing their users will also help them to create engaging 
content and experiences to which users can easily relate; consequently making it easy to recruit or involve volunteers in the organization.

Most organizations that do not study their users typically resort to using the traditional method of volunteer engagement. However, the potency and the adoption of the traditional method of recruiting and engaging volunteers have been waning over the years. According to Barnes and Sharpe (2009), this may be because the conventional method of "volunteer management is structured in a way that prevents an enriched volunteering experience" (Barnes \& Sharpe 2009, p. 169). According to them, "overly formalizing and controlling the volunteer experience reduces pathways for engagement and opportunities for volunteers to flourish in their work" (Barnes \& Sharpe 2009, 169). The assertion of Barnes and Sharpe (2009) implies that coupled with the challenges of time constraints which prevent people from volunteering, the rigid structure of the traditional method of volunteering is also another decisive factor that discourages people from participating in the activities of nonprofit organizations.

Furthermore, Clary \& Snyder (1999) recommend that it is essential that volunteers are assigned the tasks that align with their motivations for signing up to volunteer. They state that, when volunteers are given tasks that do not satisfy their motives for volunteering, they may not enjoy the experience; and this implies that such volunteers may not stay with the organization for a long time. Simply put, their statement implies that the fulfillment of volunteer motivations is essential in the recruitment and retention of volunteers.

According to Alex Peace-Gadsby, chief commissioner of England at the Scout Association, flexible volunteering is "essential for survival and continued growth of our organization" (Weakley 2017, para. 1). She said that this is because "society has evolved and people are leading busier lives" (Weakley 2017, para. 3). Furthermore, Peace-Gadsby also advised that the volunteering experience should be designed in a way that is exciting and engaging. The reason for this is that when "the volunteers stop having fun they leave" (Weakley 2017, para. 7). Her comments imply that when the volunteers are not actualizing their motivations for volunteering to the organization, they might not continue to volunteer. Furthermore, her observations also suggest that when the volunteers are not given the freedom and flexibility to choose how they engage with the organization that they are not going to stick around for a long time.

Additionally, Rajaram (2017) states that "organizations that adopt a more flexible, openchoice approach to corporate volunteerism realize greater engagement" (para. 2) She also added that "the opposite is also true - the more limits and thresholds in place, the lower the participation and impact" (para. 2) Her statement reinforces the need to provide prospective volunteers the freedom and the opportunity to choose when and how to engage with the organizations they are interested in supporting.

\section{Research method}

Overview: We used the design thinking framework to research, ideate, and prototype this project. From an academic perspective, design thinking is a mixed-methods research and innovation process that has both qualitative and quantitative components. Design thinking adopts a human-centered approach to user research and design, and this makes it suitable for tackling problem spaces such as the one under discussion. Using design thinking also allowed us to easily transition from research to the innovation of possible solutions based on the findings from the study. Furthermore, design thinking also allowed us to gain an in-depth understanding of the problem space, and to empathize with the users for a deeper understanding of how organizations can engage them.

Participants: Fifty-five respondents from various locations, including Texas, Wisconsin, Illinois, Florida, Indiana, Nebraska, and Tennessee, provided answers to the online survey designed to gather insights into the perception of the participants on their volunteering experience. The minimum age requirement to participate in the study was 18 years. The open-ended questions gave the participants the freedom to determine the length of their responses. In addition to the survey, 10 users were also engaged in an extended empathy interviews. 
Research instruments: (a) questionnaire - an open-ended survey was administered to the respondents. The survey included 12 questions: six to test their knowledge of the missions and goals of our project partner and the other six dedicated to user experience research. The study was designed to uncover the perception of the participants on their volunteering experience (for those that have volunteered previously) or the limitations that are hindering them from volunteering (for those who have yet to volunteer). Findings from the survey were analyzed using a thematic analysis. The six user research questions were as follows:

- Have you ever done volunteer work? Yes/No. If so, please explain.

- What do you think when you hear the word "volunteer"?

- What would attract you to volunteer?

- What would you want to take away from a volunteer experience?

- What do you think when you hear the word "ambassador"?

- Have you ever considered yourself an ambassador? Yes/No. If so, please explain.

(b) Interview: an empathy research interviews were also conducted with some participants to uncover more in-depth insights into their perception of nonprofit associations and media preferences. Participants were randomly selected and were interviewed in different settings and times. The empathy interview allowed us to move beyond the formality and the structured nature of the survey and to probe more and also ask follow-up questions where necessary. The interview also allowed the participants to share their experience via stories against the short comments they supplied in the survey. Some of the interview questions included:

- What do you know about the International Committee of the Red Cross?

- What do you believe makes a story stand out/stick with you over time? Do you follow any NGO on social media? Why or why not?

- What was it that attracted you to an NGO, what would put you off from viewing an image or story?

- What kind of content would you like to see on the social media accounts of The International Committee of the Red Cross? Why?

- How would you want the Red Cross to feature these stories?

- What do you think are the main interests of the younger generation?

- What types of content genre in media do you (or younger audiences) shy away from?

- How can the Red Cross engage the younger audience via social media?

- How would you explain a sad story in a way that still gives hope?

(c) Literature Review/Academic Research: in addition to the survey and interview, a literature review was employed to evaluate the work that has been done by other researchers to learn from their findings. Specifically, the literature review sought to uncover the connection between social media usage and volunteerism, images and the motivation to volunteer, and the effect of traditional media on one's motivation to volunteer. The researchers also reviewed other successful social media campaigns like the KONY 2012, ALS ICE Bucket challenge, and the Humans of New York to uncover the attributes that made them successful.

\section{Results}

The project employed the qualitative and quantitative aspects of design thinking to investigate the best approach for recruiting and engaging volunteers. Findings from the study revealed that participants would want to know that their volunteering activities are making a difference. It also showed that the participants are interested in a flexible approach to volunteering and that they would want to get some reward for helping the organizations. The headings below chronicle the findings from the study.

Survey Results: When the participants were asked if they have ever done volunteer work, 96\% of the respondents said yes while $4 \%$ of the respondents said that they have never volunteered. Some of the participants shared stories about their volunteering experience with organizations like Habitat for Humanity, Local Shelters, Big Brothers Big Sisters, and others. 
When the participants were asked what they think of when they hear the word volunteer, various themes emerged: service to others, helping others and giving back, taking a large chunk of time out of the day, time commitment, an effort that may or may not make a difference, free labor, extra work, not getting paid, cleaning the river, picking up garbage, and others.

When they were asked what would attract them to volunteer, the common themes were, a good cause, knowing that they are making a difference, pictures of others volunteering, easy to reach location, free food, rewarding experience and others. Similarly, when the participants were asked what they would want to take away from a volunteer experience, some of the responses were: new connections, new skills, some form of compensation, feeling of goodwill, knowing what I do is making a difference, social interactions with the people I'm helping, time with friends, free food.

When the participants were asked what they think of when they hear the word "ambassador," some the responses were: representative, leader, the face of a group, advocate, influence for a brand, role model, a worthy person, speaks on behalf of a group. Furthermore, when the participants were also asked whether they have ever considered themselves an ambassador, the respondents shared their experience on the times that they served as the face or the leader of an organization or a group.

Interview: Findings from the interview revealed that most of the participants were unaware of the mission and vision of our project partner, it also revealed the need to educate the audience first on the goals of the organization before attempting to recruit them to serve either as volunteers or as donors. The interview also revealed that a significant number of the sampled population were not bothered by the goals and the mission of our project partner. However, they would be interested in participating when their friends join or if there was some free food. The respondents also stated that they will be interested in stories that shows that things are getting better. Our stories that offer hope rather than the typical disaster images that are associated with the International Committee of the Red Cross.

Academic Research/Literature Review: Findings from the academic literature on the connection between social media and volunteerism showed that organizations that show empathy to their audience have more retention and interaction rates (Crompton 2018). Furthermore, the findings also revealed that social media campaigns could be energized through physical events (Gerbaudo 2012). The academic literature on the connection between images and motivation showed that photographs play a crucial role in the communication of humanitarian issues to the target audience (de Laat 2017). Similarly, a review of the effect of traditional media on people's motivation to volunteer showed that users prefer social media to traditional media because it helps them to engage and provide immediate feedback in a way that is often not available in the traditional media (Beheshti-Kashi \& Makki 2013). A review of the KONY 2012, The ALS ICE Bucket challenge, and the Humans of New York social media campaigns showed that the use of physical events in the social media campaigns was instrumental in the positive outcomes of the various campaigns.

\section{Innovation method}

Based on the findings from the research, we used the design thinking framework to transition to the ideation of possible solutions for the problem space. Design thinking is a "human-centered approach to innovation that draws from the designer's toolkit to integrate the needs of people, the possibilities of technology, and the requirements for organizational success" (IDEO U 2018). According to Brown and Wyatt (2010) "design thinking incorporates constituent or consumer insights for in-depth ideation and rapid prototyping, all aimed at getting beyond the assumptions that block effective solutions" (para. 8). It is best suited for acquiring ideas related to an audience or user behaviors, which can then be used to design successful recruitment marketing content or social media campaigns. Using the five phases of design thinking - empathize, define, ideate, prototype, and test (Whearley 2017), we developed, and a prototyped a framework that can be used by nonprofits to recruit and retain volunteers. Each phase of design thinking serves a unique role in guiding the design to a solution that will apply to different types of prospective volunteers. The next section details the framework that was designed based on the findings from the research. 


\section{The Framework}

Findings from the research showed that prospective volunteers would love to acquire new connections, new skills, some form of compensation, and the feeling of goodwill from their volunteering experience. The volunteers would also want to know that what they are doing is making a difference and that they are making the lives of other people better. However, some of them were concerned that volunteering would take a large chunk of time out of their day.

Furthermore, a common theme that emerged from the literature review was that the use of images is very crucial to the communication strategies of nonprofits. The literature review also showed that users prefer to use social media than traditional media for their information needs and that real events can energize social media campaigns. It also revealed that physical events are very vital to the success of social media campaigns and vice versa.

Based on these findings, we developed a framework that intends to enhance the volunteering experience. The primary goal of the process is to allow volunteers to influence the outcome of their volunteering experience and to give nonprofits more options on how to engage their volunteers. A secondary goal is to ensure that the volunteers enjoy their volunteering experience and to continue to be interested in supporting the organization. The steps that are highlighted in the process-flow are meant to serve as a guide to the organizations that use this process. The nonprofits that adopt this process are free to adjust the sequence of the process to suit the outcomes they desire. However, the greatest benefit would be achieved by implementing all processes in this framework.

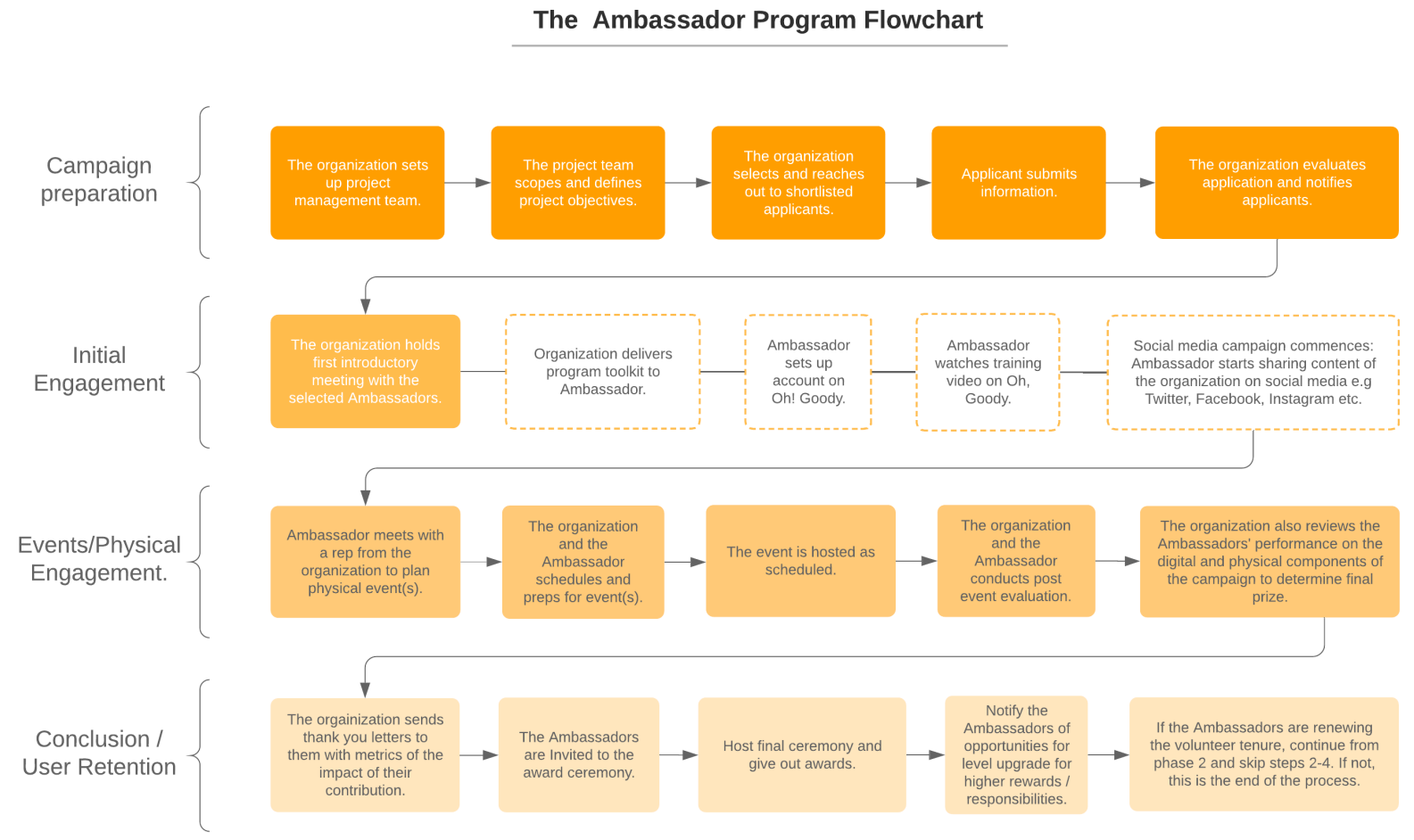

Figure 1. The flowchart for a flexible approach to volunteer engagement

The process of implementation includes four major phases. Undergoing the procedures will help the nonprofits that use the framework to be ready for every step of the campaign. It will also help to keep them organized, and also give them the ability to monitor the success of the campaign.

The phases include:

1. Campaign Preparation Phase.

2. Initial Engagement Phase.

3. Events/Physical Engagement Phase.

4. Project Conclusion and User Retention phase. 
1. Campaign Preparation Phase: Project preparation is the first phase of the program. This stage involves laying the groundwork of the different aspects of the project to ensure that the requirements are adequately articulated and defined. Articulating and defining the project objectives increases the likelihood of a successful campaign or project. Some of the steps to be undertaken at this stage include:

a. Setting-up the project management team: The goal is to ensure that the different team members - Project Manager, Content Creator, Support Analyst, among others - take ownership of the various aspects of the program. The team members are expected to be assigned tasks that suit their capabilities. In most cases they are to serve as support staff to the ambassadors, that is persons the ambassadors can easily reach out whenever they have specific questions. For organizations with fewer human resources and a small number of ambassadors, the task of the committee can be handled by a single dedicated staff member.

b. Defining the project objectives: Here the organization is expected to clearly define the goals they wish to achieve with the project - fundraising, recruiting more volunteers, creating awareness of the organization's mission and goals, community outreach, disaster relief among others. Defining the project goals will help the organization to define the metrics that can be used to determine a successful campaign. For instance, with a fundraising goal of $\$ 2,000$ at the end of the campaign, the organization can be able to determine if the campaign was a success or not. Similarly, with a recruitment goal of 200 new volunteers in 2 months, at the end of the campaign, the organization should be able to determine if the project was a success. It should be noted that fundraising and recruitment goals in addition to other objectives can be a part of a much broader campaign.

c. Define who can become an ambassador: At this stage, the organization determines the characteristics they want in prospective ambassadors. It is important to note that the goals that the organization wants to achieve should influence the kind of ambassador they recruit. For example, do we want people with a strong following on social media so we can leverage their popularity to reach more audience? Do we need people with social work degrees?

d. Ambassador application: Recruiting volunteers is often a difficult task for nonprofit associations. Therefore, it is recommended that the organization should start with the volunteers that are already engaged to reach out into their personal networks. The goal is to build up the numbers gradually. At this stage, the selected ambassadors should complete an application form if they have not done so before. It is essential that the right set of questions are asked at this point to ensure that the organization obtains an in-depth knowledge of the inclinations of the potential ambassadors before recruiting them.

e. Application evaluation: at this phase, the organization evaluates the application to ensure that the information that is submitted by the participants matches the parameters that they established for the prospective ambassadors.

f. Applicant approval: The last thing at this phase is to notify the applicants if their application has either been accepted or rejected. For those that have been denied, the organization can engage them through other ways than becoming an ambassador.

2. Initial Engagement Phase: The significant activities that will take place in this phase include:

a. First meeting: The organization holds the first meeting with the ambassador to discuss the kind of duties they would want to undertake. For example, if the goals the organization had set in the project preparation phase were to create awareness, recruit volunteers or raise money, the ambassador could choose an option and then decide how they want to achieve this goal and also how much time they may need to do so. They can also choose the size of their deliverable. The ambassador is also free to recruit more volunteers such as friends and family to help achieve this objective. The ambassadors can also form a group to help pool their resources together. This stage is the defining moment of the process. In the traditional approach, volunteers are typically assigned tasks. In this process, however, the volunteers are given the freedom to choose how they want to assist the organization and the frequency 
of their participation. The goal of the nonprofit is to support the volunteers to achieve their goals on behalf of the organization.

b. The organization delivers toolkit to the ambassador: After the initial meeting, the organization would provide a programming toolkit to the ambassador. This toolkit should outline the obligations, constraints and requirements of their tasks. This ensures that regardless of the activities the ambassador chooses, their message should not stray from the mission and core values of the organization.

c. Account set-up: The next step is to ensure that the ambassadors register on the digital tools used to coordinate the campaign. At this stage, the organization will also train the ambassadors to ensure that they are adequately equipped to achieve their objectives. This can be achieved using brand engagement platforms like Oh, Goody.

d. Commencement of social media campaign: After registering on the digital platforms and completing the required training, the ambassadors that chose the creation of awareness as their primary task can commence sharing content on social media, within required parameters. For those that are interested in helping in other ways other than sharing content on social media, they can choose physical events as highlighted in the next stage. It is recommended that the ambassadors that did not sign-up to share content on social media should be encouraged to share images of themselves helping the organization on social media. Brand engagement platforms like Oh, Goody are very crucial at this stage. Platforms such as this are vital because the organization can use them to monitor engagement of ambassadors with training videos, track social media metrics for pushed content. Also, the organization can use the platform to reward ambassadors and volunteers for watching training videos or for sharing the content of the organization on social media. Rewarding volunteers and ambassadors for every activity they complete gamifies the experience and encourages them to do more.

3. Events/Physical Engagement Phase: The primary activities that take place at this stage include the following:

a. Planning Events: Ambassadors that chose to organize events like recruitment drives and fundraising efforts will need to meet with the representatives of the organization to plan and schedule for the activities to ensure that they are a success. This meeting can either be a physical or virtual meeting depending on the schedule of the ambassador. The ambassadors and the organization should collaborate to set goals that both meet the needs of the organization and engage the volunteer with flexible and meaningful tasks. The goal of the organization is to support the ambassadors to achieve their goals and not to blindly dictate to them.

b. Hosting Events: Physical events, such as a bowling competition, a dancing competition, fundraising dinners, and volunteer drives foster deeper and more personal engagement with the community. The type of event held depends on the skills of the ambassador and the goals they and the organization want to achieve.

c. Campaign Evaluation: The last step of this stage is for both parties to evaluate the outcome of the event and determine areas that require further improvement. This can be achieved using the Plus/Delta $(+/ \Delta)$ format of evaluation. Plus highlights the things they did well, and delta areas that need improvement.

4. Project Conclusion and User Retention phase: This phase is the final part of the process. The goal of this stage is to reward volunteers for their contribution and retain them in the system. They can choose to repeat the tasks they completed or set new goals.

a. The first step of this phase is to send a personalized thank you note or letter to the ambassadors with the metrics of the impact of their contribution. This thank you note will also contain a letter inviting them to a final awards ceremony. The metrics of the impact of their activities can be generated from the Oh, Goody platform. This platform makes it easy 
to keep track of the engagement rates of the content that is being shared by the ambassador or the organization. The metrics can include the number of times their posts were liked, shared or retweeted. It can also include the number of people that were reached by their posts, among other details. Showing the volunteers the impact of their actions will encourage them to do more and leave them satisfied that their contributions made a difference.

b. The second step is to host the closing ceremony and present awards to the ambassadors that have completed their term. The awards ceremony is an opportunity to notify ambassadors that they can renew their program and are free to choose new goals that fit their availability. The organization should use the metrics to remind the volunteers that their contributions will be missed if they stop volunteering.

\section{Conclusion}

The goal of developing this framework was to avail nonprofits a new method of volunteer management. At the end of the campaign, the organization should expect to see a significant improvement in their ability to recruit and retain volunteers and donors, likewise an increase in volunteer satisfaction.

\section{Acknowledgment}

We want to thank our faculty advisor, Dr. Kevin Moloney for his guidance and support in the course of writing this paper. We also want to thank Big Brothers Big Sisters of East Central Indiana led by Sue Godfrey for accepting to work as our project partners in the course of testing the process.

\section{References}

Barnes, M. L., \& Sharpe, E. K. 2009. "Looking Beyond Traditional Volunteer Management: A Case Study of an Alternative Approach to Volunteer Engagement in Parks and Recreation." VOLUNTAS: International Journal of Voluntary and Nonprofit Organizations 20(2): 169-187. doi:10.1007/s11266-009-9080-5.

Barrett, H., Balloun, J. L., \& Weinstein, A. 2005. "The impact of creativity on performance in non-profits." International Journal of Nonprofit and Voluntary Sector Marketing 10(4): 213-223. doi:10.1002/nvsm.25.

Beheshti-Kashi, S., \& Makki, B. 2013. "Social Media News: Motivation, Purpose and Usage." International Journal of Computer Science and Information Technology 5(2): 97-105. doi:10.5121/ijcsit.2013.5209.

Brown, T., \& Wyatt, J. 2010. "Design Thinking for Social Innovation. Retrieved from Stanford Social Innovation Review." Available at https://ssir.org/articles/entry/design_thinking_for_social_innovation.

Clary, E. G., \& Snyder, M. 1999. “The Motivations to Volunteer.” Current Directions in Psychological Science 8(5): 156-159. doi:10.1111/1467-8721.00037.

Crompton, J. C. 2013, February 08. "Real or Fake: Social Media Empathy - The social Media Monthly." Retrieved from https://thesocialmediamonthly.com/real-or-fake-social-media-empathy/.

De Laat, S. 2017, December. "Regarding Aid: The photographic situation of humanitarianism." Retrieved from https://ir.lib.uwo.ca/cgi/viewcontent.cgi?article=6906\&context=etd.

Durham, J. 2016, June 11. "Flexible Volunteering." Voluntary Worker. Retrieved from http://www.voluntaryworker.co.uk/FlexibleVolunteering.html.

Gerbaudo, P. 2012. Tweets and the streets: Social media and contemporary activism. London: Pluto Press.

IDEO, U. 2018. “Design thinking.” Retrieved from IDEO U: https://www.ideou.com/pages/design-thinking.

Rajaram, A. 2017, February 1. "Volunteering Reimagined: 5 Ways to Energize Employee Engagement. Retrieved from Benevity." Available at https://insights.benevity.com/blog/volunteering-reimagined-5-ways-to-energizeemployee-engagement.

Sahni, N., Lanzerotti, L., Bliss, A., \& Pike, D. 2017, August 01. "Is Your Nonprofit Built for Sustained Innovation?" Stanford Social Innovation Review. Retrieved from https://ssir.org/articles/entry/is_your_nonprofit_built_for_ sustained innovation.

Silverstein, J. 2017, April 10. “4 Challenges Facing Nonprofits In 2017 And How To Overcome Them.” Not Your Father's Charity. Retrieved from http:/www.notyourfatherscharity.com/blog/4-challenges-facing-nonprofits-in2017-and-how-to-overcome-them/.

Weakley, K. 2017, June 5. “'Flexible volunteering essential for survival' says Scout Association commissioner.” Civil Society Media. Retrieved from https://www.civilsociety.co.uk/news/offer-more-flexible-volunteeringopportunities-to-lure-people-away-from-boxsets.html.

Whearley, N. 2017, February 07. (archival resource) "Design Thinking Bootcamp Bootleg." Retrieved from https://dschool.stanford.edu/resources/the-bootcamp-bootleg. 